ARTICLE

Received 7 May 2014 | Accepted 25 Jun 2014 | Published 24 Jul 2014

DOI: $10.1038 /$ ncomms5514

\title{
PINK1 deficiency sustains cell proliferation by reprogramming glucose metabolism through HIF1
}

Raquel Requejo-Aguilar ${ }^{1,2}$, Irene Lopez-Fabuel ${ }^{1,2}$, Emilio Fernandez ${ }^{1,2}$, Luis M. Martins ${ }^{3}$, Angeles Almeida ${ }^{1,2}$ \& Juan P. Bolaños ${ }^{1,2}$

PTEN-induced kinase-1 (PINK1) is a Ser/Thr kinase implicated in familial early-onset Parkinson's disease, and was first reported as a growth suppressor. PINK1 loss-of-function compromises both mitochondrial autophagy and oxidative phosphorylation. Here we report that PINK1 deficiency triggers hypoxia-inducible factor-1 $\alpha$ (HIF1 $\alpha$ ) stabilization in cultured Pink $1^{-/-}$mouse embryonic fibroblasts and primary cortical neurons as well as in vivo. This effect, mediated by mitochondrial reactive oxygen species, led to the upregulation of the HIF1 target, pyruvate dehydrogenase kinase-1, which inhibits PDH activity. Furthermore, we show that HIF1 $\alpha$ stimulates glycolysis in the absence of Pink1, and that the promotion of intracellular glucose metabolism by HIF1 $\alpha$ stabilization is required for cell proliferation in Pink $1^{-/-}$mice. We propose that loss of Pink1 reprograms glucose metabolism through HIF1 $\alpha$, sustaining increased cell proliferation.

\footnotetext{
${ }^{1}$ Institute of Functional Biology and Genomics (IBFG), University of Salamanca-CSIC, 37007 Salamanca, Spain. ${ }^{2}$ Institute of Biomedical Research of Salamanca (IBSAL), University Hospital of Salamanca, 37007 Salamanca, Spain. ${ }^{3}$ MRC Toxicology Unit, Hodgkin Building, Leicester LE1 9HN, UK. Correspondence and requests for materials should be addressed to J.P.B. (email: jbolanos@usal.es).
} 
$\mathrm{P}$ arkinson's disease (PD) is the second most common neurodegenerative disease, affecting $1-2 \%$ of people over 65 years of age. PD is characterized by the loss of dopaminergic neurons and the development of intracellular aggregates of the protein $\alpha$-synuclein. Currently, it is widely accepted that mitochondrial dysfunction is a key factor in $\mathrm{PD}$ pathogenesis ${ }^{1}$. While the vast majority of PD cases are sporadic, $5-10 \%$ of cases are inherited through mutations in PD-related genes. There is now compelling evidence supporting the notion that the autosomal recessive early-onset PD-related genes PTENinduced kinase-1 (PINK1) and PARKIN are key regulators of the mitochondrial quality control ${ }^{2,3}$.

Full-length PINK1 localizes to the mitochondrial outer membrane $^{3,4}$, where it interacts-in a phosphorylationdependent manner-with PARKIN ${ }^{5,6}$, both acting on the same pathway as a quality control system to preserve mitochondrial integrity on mitochondrial membrane potential $\left(\Delta \psi_{\mathrm{m}}\right)$ collapse. Thus, loss of PINK1, or disease-relevant mutations in PINK1 gene, compromises mitochondrial autophagy ${ }^{7-10}$, as well as mitochondrial oxidative phosphorylation, predominantly at the level of complex $\mathrm{I}^{11,12}$

Besides its role in PD, PINK1 was reported to have a growth suppressive function ${ }^{13}$ through a yet unravelled mechanism. Given that cell proliferation requires, among other metabolic adaptations, a high glycolytic rate ${ }^{14}$ and, in view of its mitochondrial protection role, we hypothesized that PINK1 might act by modulating glycolysis. Here, we show that the loss of Pink1 reprograms glucose metabolism through hypoxia-inducible factor- $1 \alpha$ (HIF1 $\alpha)$ to stimulate glycolysis. Unexpectedly, we found that the glycolytic reprogramming is required for the increased cell proliferation observed on loss of Pink1.

\section{Results}

Loss of Pink1 stimulates glucose metabolism. To elucidate whether PINK1 regulates glucose metabolism, we first obtained Pink1 $1^{-/-}$(Pink1 knockout or KO) and Pink1 ${ }^{+/+}$(wild type or WT) primary mouse embryonic fibroblasts (MEF) from the same offspring. The rates of glucose uptake (Fig. 1a) and glycolysis (Fig. 1b,c) in Pink1 KO MEF were approximately twofold higher when compared with WT. Instead, the rate of glucose utilization through the pentose-phosphate pathway (PPP) was $\sim 45 \%$ lower in Pink1 KO MEF than in WT (Fig. 1d), indicating the shift of glucose-6-phosphate consumption from PPP towards glycolysis that also takes place in other biological settings ${ }^{15}$. To extend these findings to non-proliferating cells, we next assessed glucose metabolism in cultured primary cortical neurons. As shown in Fig. 1e-g, loss of Pink1 in neurons triggered a $\sim$ twofold increase in the rates of glucose uptake and glycolysis when compared with WT. The flux of glucose consumption through the PPP was reduced in a similar extent in Pink1 KO neurons (Fig. 1h), suggesting metabolic shift from PPP to glycolysis in neurons. We next sought to confirm the enhanced glucose metabolism in vivo. We found that Pink1 KO mice were slightly hypoglycaemic (Fig. 1i) and hyperlactatemic (Fig. 1j). In addition, the rate of ${ }^{14}$ C-lactate appearance in the blood from acutely injected $\left[\mathrm{U}_{-}{ }^{14} \mathrm{C}\right]$ glucose mice was higher in Pinkl KO than in WT (Fig. 1k). Together, these results indicate that the loss of Pink1 causes a metabolic reprogramming that promotes glucose uptake and glycolysis.

Glucose-utilizing enzymes and HIF1 $\alpha$ are altered on loss of Pink1. To investigate whether the changes in glucose metabolism a
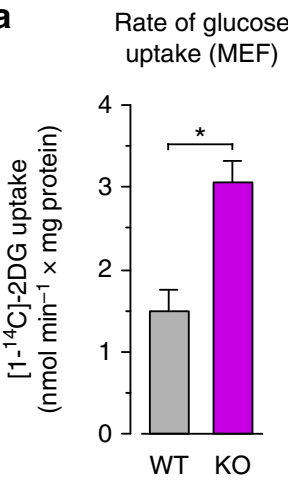

f

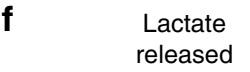

released

(neurons)

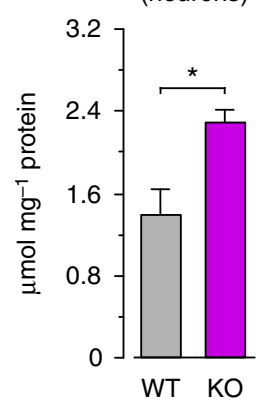

b
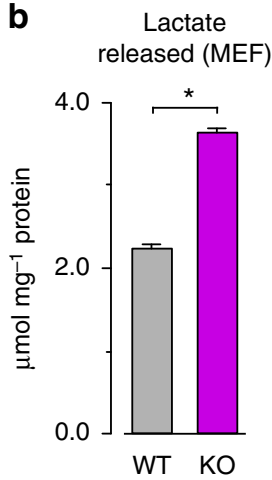

C

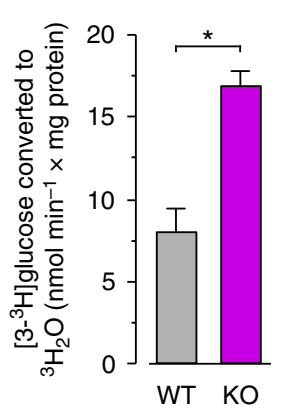

d

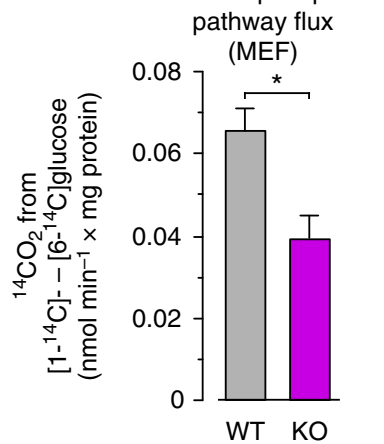

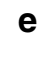

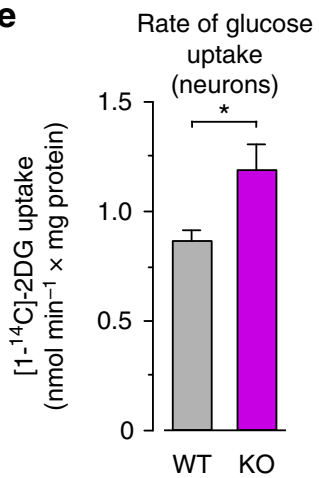

g Glycolytic flux $\mathbf{h}$ (neurons)

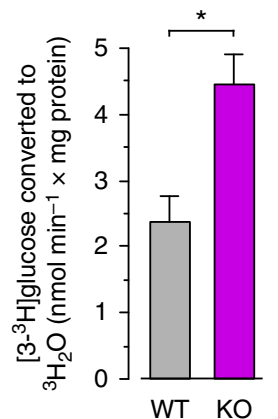

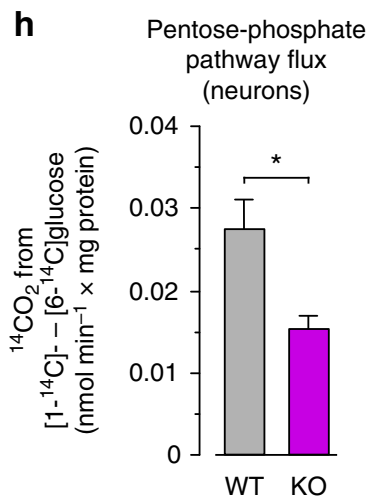
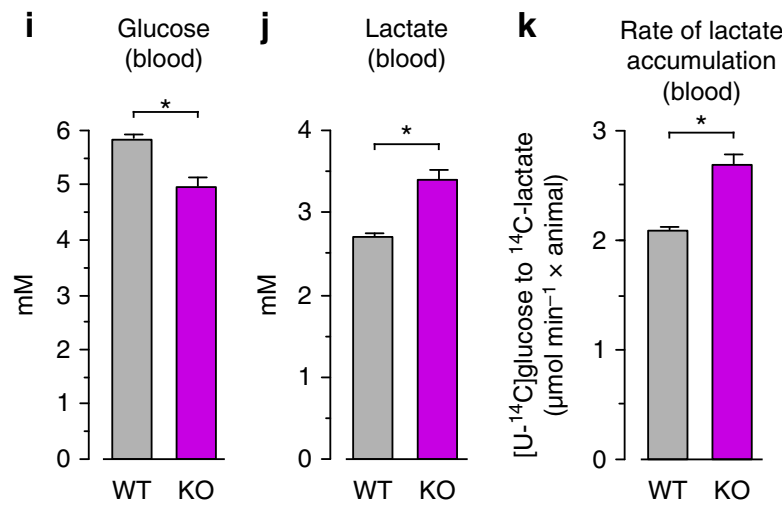

Figure 1 | Enhanced glucose metabolism on loss of Pink1. The rate of glucose uptake (a,e), lactate released after $4 \mathrm{~h}$ of incubation (b,f), glycolytic flux $(\mathbf{c}, \mathbf{g})$ and pentose-phosphate flux ( $\mathbf{d}, \mathbf{h})$ were assessed in MEF and mouse cortical neurons in primary culture, as indicated, obtained from either WT or Pink1 $\mathrm{KO}\left(\right.$ Pink $\left.1^{-/-}\right)$mice. Blood concentrations of glucose $(\mathbf{i})$ and lactate $(\mathbf{j})$, and the rate of ${ }^{14} \mathrm{C}$-lactate appearance in the blood from acutely injected $\left[\mathrm{U}-{ }^{14} \mathrm{C}\right]$ glucose in the tail vein $(\mathbf{k})$ of WT and Pink1 KO mice were analysed. Data are expressed as mean \pm s.e.m. ${ }^{\star} P<0.05$ (Student's $t$-test; $n=3-4$ independent experiments). 
observed by the loss of Pink1 were associated with alterations in the expression of glycolytic enzymes, we next analysed the relative messenger RNA (mRNA) abundance of key glucose-metabolizing enzymes. As shown in Fig. 2a, glucose transporter-1 (Glut1), glucose transporter-3 (Glut3), hexokinase-2 (Hk2) and glyceraldehyde-3-phosphate dehydrogenase (Gapdh) mRNA abundances, relative to those of the housekeeping $\beta$-Actin, were 1.5-2.5-fold higher in Pink1 KO MEF when compared with WT. The relative mRNA abundance of other key glycolytic enzymes, including 6-phosphofructo-2-kinase/fructose-2,6bisphosphatase-3, enolase-1 and lactate dehydrogenase-a, but not that of hexokinase-1), albeit very slightly, were also higher in the Pink1 KO MEF than in WT (Supplementary Fig. 1a). The protein levels of GLUT1, HK2 and GAPDH were also increased in the Pink1 KO MEF (Fig. 2b; Supplementary Fig. 1b); GLUT3 protein was undetectable in MEF (not shown). As these transporters and enzymes are well-known targets of hypoxia-inducible factor-1 (HIF1), we next investigated the abundance of its $\alpha$-subunit $(\mathrm{HIF} 1 \alpha)$ that is amenable to regulation by protein stability ${ }^{16}$. As shown in Fig. 2b, HIF1 $\alpha$ protein was increased in MEF lacking Pink1 (see, also, Supplementary Fig. 1b). Since this effect cannot be ascribed to a putative increase in Hifl $\alpha$ mRNA abundance (Hifl $\alpha$ levels in Pink1 KO MEF were found to be 0.49 plus or minus $( \pm)$ 0.07-fold, normalized to B-actin, when compared with WT; $n=3$ ), our data indicate the stabilization of HIF1 $\alpha$ in the Pink1 KO MEF. Likewise, cultured primary neurons from the Pink1 KO mice had 1.4-1.8-fold enhancement in the mRNA abundances of Glut1, Glut3, Hk2 and Gapdh when compared with WT (Fig. 2c). The corresponding proteins were increased accordingly (Fig. 2d; Supplementary Fig. 1c). In Pink1 KO neurons, HIF1 $\alpha$ protein-but not its mRNA (Hif $\alpha$ levels in Pink1 KO neurons were found to be $0.43 \pm 0.11$-fold, normalized to B-actin, when compared with WT; $n=3$ )-was higher than in WT (Fig. 2d; Supplementary Fig. 1c). To extend our observations to in vivo settings, we confirmed the upregulation of GLUT1, GLUT3 and HIF1 $\alpha$ in skeletal muscle of Pink1 KO mice (Figs 1d,2e). In addition, we performed a microRNA (miR) transcription profiling in Pink1 KO mice brain, which revealed significantly elevated several miRs, such as $m i R-30 b-5 p$,
miR-26b-5p, miR-27a-3p, miR-181c-5p, miR-494-3p and miR-30d$5 p$ that are reported to modulate $\operatorname{HIF} 1 \alpha$ repression ${ }^{17}$ (Supplementary Table 1). Thus, our data indicate HIF1 $\alpha$ stabilization in the Pink-null mice, and HIF1 $\alpha$-target proteins enhancement likely contributing to the observed glucose metabolism reprogramming.

HIF1 $\alpha$ is required for increased glycolysis on Pink1 loss. To directly demonstrate the involvement of HIFl $\alpha$ in the glycolytic phenotype caused by loss of Pink 1 , we explored the consequences of its removal by RNA interference. As shown in Fig. 3a, transfection of MEF with a small interfering RNA (siRNA)

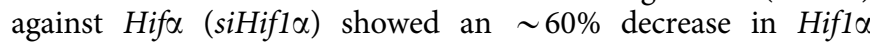
mRNA abundance when compared with controls. This effect was selective since siHifl $\alpha$ was unable to knockdown the HIF1 $\alpha$ protein that was expressed from a mutant form of Hifl $1 \alpha \mathrm{cDNA}$ harbouring silent mutations on its siRNA-target region (Fig. 3b; Supplementary Fig. 2a). HIF1 $\alpha$ knockdown fully prevented the increase in the Glut1, Glut3, Hk2 and Gapdh mRNA abundance (Fig. 3c), and in the GLUT1 and GAPDH (Fig. 3d; Supplementary Fig. 2b) protein abundance of the Pink1 KO MEF. Furthermore, the increased lactate released (Fig. 3e) and glycolytic rate (Fig. 3f) promoted by PINK1 loss-of-function was rescued by knocking down HIF1 $\alpha$. Likewise, knocking down HIF $1 \alpha$ in primary neurons (Fig. 3g; Supplementary Fig. 2c) fully abolished the increase in the glycolytic rate exerted by PINK loss-of-function (Fig. $3 \mathrm{~h}$ ). Together, these data strongly suggest that HIF $1 \alpha$ is required for the enhanced glycolytic phenotype caused by the loss of Pinkl.

Mitochondrial ROS mediate HIF1 $\alpha$ stabilization on Pink1 loss. To understand how the lack of PINK1 upregulated HIF1 $\alpha$, we first confirmed the defects in both mitochondrial respiratory chain (Fig. 4a) and inner membrane potential (Fig. 4b) of Pinkl KO MEF that were previously reported in similar settings ${ }^{11,18}$. Moreover, we found that pyruvate dehydrogenase kinase-1 (PDK1) protein abundance, a known HIF1-target ${ }^{19}$, was higher in Pink1 KO MEF when compared with WT (Fig. 4c; Supplementary Fig. 2e). In addition, we found that the increase

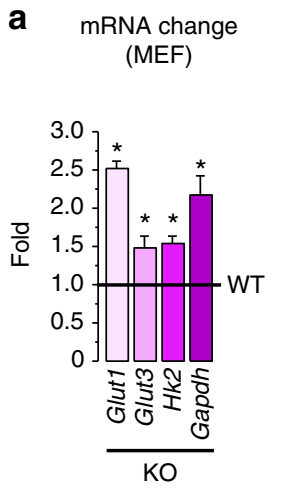

$\mathrm{KO}$

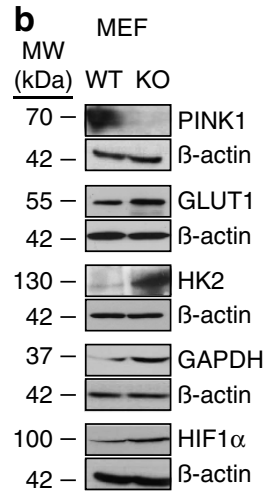

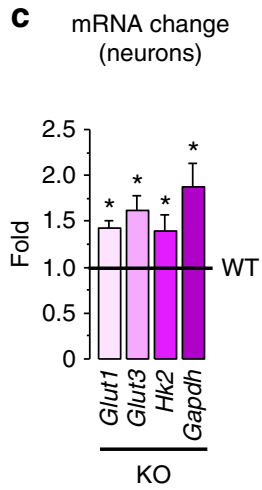

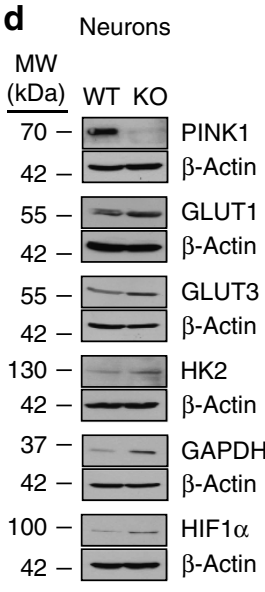

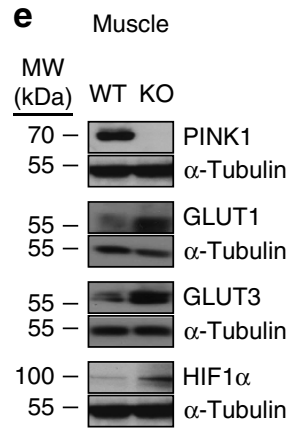

Figure 2 | Glucose-utilizing enzymes and HIF1 $\alpha$ are altered by Pink1 loss. Quantitative real-time PCR (RT-qPCR analysis of the relative mRNA abundances of Glut1, Glut3, Hk2 and Gapdh in WT and Pink1 KO mice MEF (a) or neurons (c). B-Actin mRNA was used for normalization, and the Pink1 KO data are expressed as the change relative to WT. Western blot analysis of the protein abundances of PINK1, GLUT1, GLUT3 (not detectable in MEF), HK2, GAPDH and HIF1 $\alpha$ in WT and Pink1-null mice MEF (b) or neurons (d); B-Actin was used as loading control. (e) Western blot against PINK1, GLUT1, GLUT3 and HIF1 $\alpha$ in WT and Pink1 KO mice skeletal muscle samples; $\alpha$-Tubulin was used as loading control. Only representative western blots are shown per condition; the replicates and the semi-quantitative estimation of the band intensities are shown in the Supplementary Information. The mean \pm s.e.m. values of the mRNA data were calculated from the fold change of each $\beta$-Actin-normalized transcript abundance in the Pink1 KO samples versus that in the WT. Thus, in all cases, the WT values were considered $=1.00$. ${ }^{\star} P<0.05$ versus the corresponding WT (Student's $t$-test; $n=3-4$ independent experiments). 
a

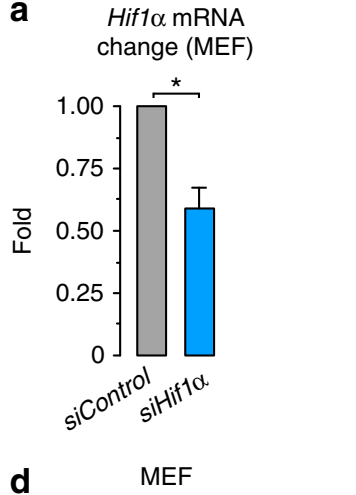

b

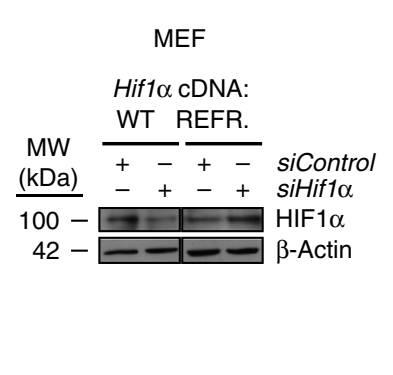

c

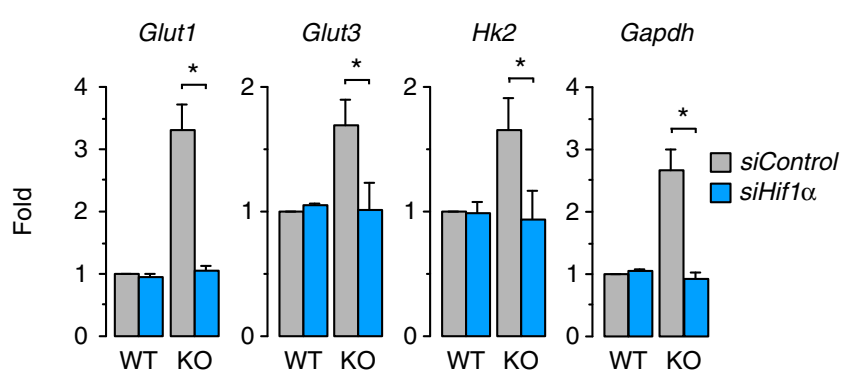

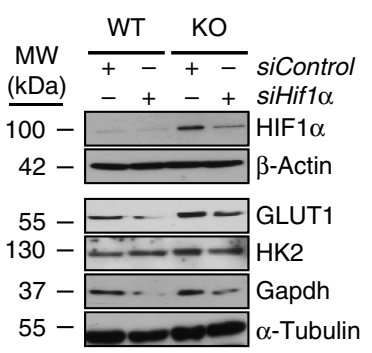
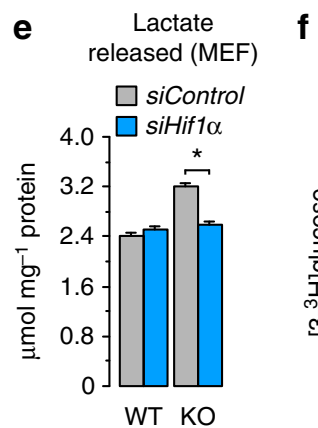

f

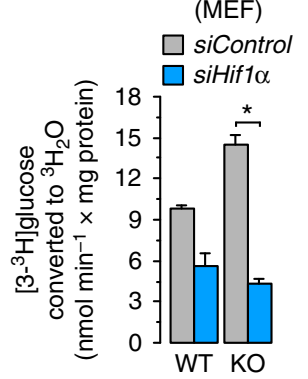

h

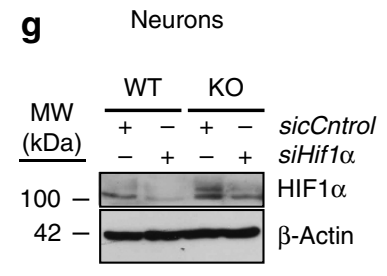

h Glycolytic flux (neurons)

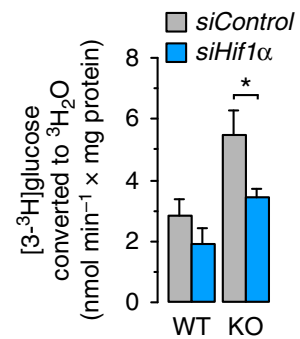

Figure 3 | HIF1 $\alpha$ is required for increased glycolysis by Pink1 loss. An siHif1 $\alpha$ was used to evaluate its involvement in the glycolytic phenotype of Pink1 KO cells. (a) RT-qPCR analysis of Hif1 $\alpha$ mRNA abundance in MEF transfected with siHif1 $\alpha$, or siControl (100 nM), after $72 \mathrm{~h}$. (b) siHif1 $\alpha$ effectively knockdowns expressed Hif1 $\alpha$ cDNA WT, but not a Hif1 $\alpha$ cDNA silent mutant form refractory to siHif1 $\alpha$ (Hif1 $\alpha$ cDNA REFR.) in mice MEF. (c) RT-qPCR analysis of the relative mRNA abundances of Glut1, Glut3, Hk2 and Gapdh in WT and Pink1 KO mice MEF transfected with siControl or siHifla. B-Actin mRNA was used for normalization, and all data are expressed as the change relative to WT-siControl. (d) Western blot against HIF1 $\alpha$ in WT and in Pink1 KO mice MEF transfected with siHif1 $\alpha$ or siControl shows the efficacy of the siHif1 $\alpha$ at knocking down endogenous HIF1 $\alpha$; $\beta$-actin was used as loading control. As shown, siHif1 $\alpha$ partially prevented the increase in GLUT1, HK2 and GAPDH protein abundances. The increased rate of lactate released after $4 \mathrm{~h}$ of incubation (e) and glycolytic flux (f) observed in the Pink1 KO MEF was prevented by siHif1 $\alpha$. siHif1 $\alpha$ was also effective at preventing the endogenous increased HIF1 $\alpha$ protein $(\mathbf{g})$, as well as the increased glycolytic flux (h) observed in Pink $1 \mathrm{KO}$ primary neurons. Only representative western blots are shown; the replicates and the semi-quantitative estimation of the band intensities are shown in the Supplementary Information. The mean \pm s.e.m. values of the mRNA data were calculated from the fold change of each B-actin-normalized transcript abundance in the Pink1 KO samples versus that in the WT (a) or WT-siControl (c); thus, in all these cases, the WT (a) or WT-siControl (c) values were considered $=1.00$. Only the statistical analysis results of the siHifla versus siControl (in $\mathrm{KO}$ ) values (mean \pm s.e.m.) are shown in $\mathbf{c}, \mathbf{e}, \mathbf{f}, \mathbf{h}$, since the comparison $\mathrm{KO}$ versus WT under control conditions was previously shown in Fig. $2 \mathrm{a}$, Fig. $1 \mathrm{~b}, \mathrm{c}, \mathrm{g}$, respectively. ${ }^{\star} P<0.05$ (Student's $t$-test; $n=3-4$ independent experiments).

in PDK1 protein was abolished by knocking down HIF1 $\alpha$ (Fig. 4c; Supplementary Fig. 2e). Since PDK1 phosphorylates $\mathrm{PDH}$, complex inhibiting its activity, we next determined PDH activity in the Pink1 KO MEF. As shown in Fig. 4d, PDH activity was $\sim 80 \%$ lower in Pink1 KO cells when compared with WT, and this effect was ablated by HIF1 $\alpha$ knockdown. Thus, through HIF1, PINK1 deficiency inhibits PDH activity, which likely contributes to a positive loop of mitochondrial impairment. Confirming previous work ${ }^{18}$, we found that the rates of $\mathrm{H}_{2} \mathrm{O}_{2}$ and mitochondrial $\mathrm{O}_{2}^{\bullet-}$ detected were higher in MEF from Pink1 KO mice than in the WT (Fig. 4e,f). Since these reactive oxygen species (ROS) stabilize HIF1 $\alpha^{20-22}$, we sought to assess whether mitochondrial ROS mediated the enhancement of HIF1 $\alpha$ observed by the loss of PINK1. As shown in Fig. 4g, mitochondrial $\mathrm{O}_{2}^{\bullet-}$ detection was reduced either by incubating MEF with a plasma membrane permeable form of glutathione (glutathione ethyl ester, GSH-EE), or by expressing mitochondrial-tagged forms of glutamate-cysteine ligase (mitoGCL) $)^{23}$ or catalase (mitoCAT). As depicted in Fig. $4 \mathrm{~h}$ and Supplementary Fig. 2f, the increase in HIF1 $\alpha$ protein observed in Pink1 KO MEF was decreased not only by the whole-cell ROS scavenger GSH-EE, but also by selectively removing ROS in mitochondria with mitoGCL or mitoCAT. Thus, mitochondrialderived ROS accounts for HIF $1 \alpha$ protein stabilization caused by Pink1 loss.
Increased cell proliferation on loss of Pink1 requires HIF1a. Given that PINK1 is a growth-suppressor protein ${ }^{13}$ and that increased glucose utilization supports cell growth ${ }^{14}$ through HIF1 (ref. 16), we next sought to determine whether the observed increased rate of glycolysis in Pink1 KO cells was associated with an increase in cell proliferation. To achieve this, we evaluated the rate of bromo-deoxy-uridine (BrdU) incorporation into DNA, the proportion of each cell cycle phase, and cell growth in Pink1 KO $\mathrm{MEF}$ in the absence or in the presence of the glucosemetabolizing inhibitor, 2-deoxyglucose (2DG). As depicted in Fig. 5a, Pink1 KO MEF showed a higher rate of BrdU incorporation, decreased $G_{0} / G_{1}$ phase, increased $S$ and $G_{2} / M$ phases and higher rate of proliferation (Fig. 5b) when compared with WT; moreover, 2DG fully abolished Pink1 KO-mediated increase in cell proliferation (Fig. 5a,b), indicating the requirement of glucose utilization for Pink1 KO-induced cell proliferation. In addition, the increased proliferation rate of the Pink1 KO MEF was prevented by knocking down HIF1 $\alpha$ (Fig. 5c,d), indicating the requirement of HIF1 $\alpha$ stabilization for Pink1 KO-induced cell proliferation. To confirm the high proliferative status in vivo, we analysed the neurogenic subventricular zone (SVZ) in the Pink1 KO mouse brain. As shown in Fig. 5e, we observed a $\sim$ twofold increase in Ki67-immunostained cells that were positive for the stem cell marker Sox2, confirming enhanced proliferation rate of neural 

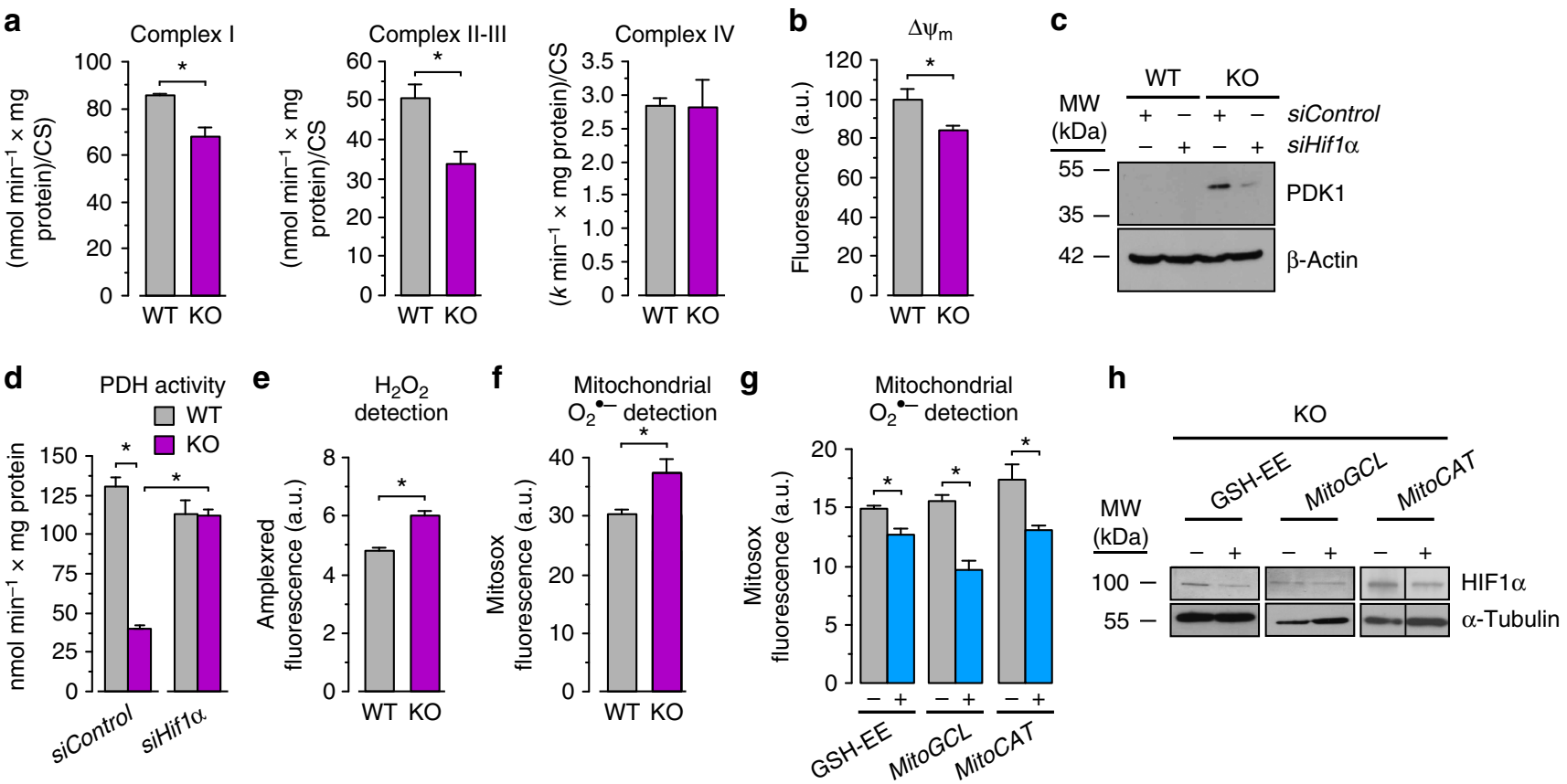

Figure 4 | Mitochondrial ROS mediate HIF1 $\alpha$ stabilization by Pink1 loss. (a) Mitochondrial respiratory chain complexes activity values normalized to citrate synthase (CS), and (b) mitochondrial inner membrane potential $\left(\Delta \psi_{\mathrm{m}}\right)$ in WT and Pink1 KO mice MEF. (c) Western blot against PDK1 and HIF1 $\alpha$ in WT and Pink1 KO MEF transfected with siHif1 $\alpha$ (or its siControl); $\beta$-actin was used as loading control. (d) PDH complex activity in WT and Pink1 KO MEF transfected with siHif1 $\alpha$ or siControl. Rate of whole-cell $\mathrm{H}_{2} \mathrm{O}_{2}(\mathbf{e})$ and mitochondrial $\mathrm{O}_{2}^{-}$(f) detection in WT and Pink1 KO MEF. (g) Detection of mitochondrial $\mathrm{O}_{2}^{-}$- using the mitochondrial-specific probe MitoSox in MEF incubated in the absence $(-)$or in the presence $(+)$of the plasma membrane permeable GSH-EE, or by expressing mitochondrial-tagged forms of glutamate-cysteine ligase, ( + mitoGCL; empty vector, pIRES2-EGFP, denoted as - ) or catalase ( + mitoCAT; empty vector denoted as - ), shows effective mitochondrial ROS removal. (h) Western blot against HIF1 $\alpha$ in Pink1 KO MEF incubated with (or without) GSH-EE, or transfected with empty vector, mitoGCL or mitoCAT, showing reduction in HIF1 $\alpha$ protein abundance by the treatments that remove mitochondrial ROS; $\alpha$-TUBULIN was used as loading control. Only representative western blots are shown; the replicates and the semi-quantitative estimation of the band intensities are shown in the Supplementary Information. Data are expressed as mean \pm s.e.m. ${ }^{\star} P<0.05$ (Student's $t$-test; $n=3-4$ independent experiments).

stem cells in vivo by Pink1 loss. Thus, our data shows that the loss of PINK1 causes an increase in cell proliferation, for which both glucose utilization and HIF $1 \alpha$ are required. Primary neurons, obtained from the Pink1 KO mice, showed higher mitochondrialderived ROS than WT (Fig. 6a), likely contributing-such as in MEF-to HIF1 $\alpha$ stabilization. However, in line with their postmitotic status, these Pink1 KO neurons showed unaltered their rate of BrdU incorporation rate (Fig. 6b); we found, instead an increased apoptotic cell death rate (Fig. 6c). Thus, the metabolic re-wiring caused by PINK1 loss-of-function, being unable to support proliferation in post-mitotic neurons, would likely be involved in a death phenotype.

\section{Discussion}

Here, we show that loss of Pink1 reprograms glucose metabolism and this is likely to meet the bioenergetic requirements for the enhanced proliferation observed in Pink1 knockout proliferating cells such as fibroblasts. Moreover, we have also identified ROS-mediated HIF1 $\alpha$ stabilization as the molecular mechanism responsible for this metabolic adaptation. According to our results obtained with mitochondrial-tagged antioxidant enzymes, mitochondrial-derived ROS are likely to play a key role in HIF1 $\alpha$ stabilization. However, the involvement of cytosolic ROS in this effect cannot be discarded. In fact, decreased catalase and peroxiredoxin have been linked to the loss of PINK1 in other vertebrates such as zebrafish ${ }^{18}$. This may also account for the ROS increase observed by us in Pink1-null cells. In addition, a decrease in Hif $1 \alpha$ mRNA has been previously reported in the Pink1 KO zebrafish ${ }^{24}$, and in Pink1 KO MEF and neurons on hypoxia ${ }^{25}$. Here, we detected higher HIF $1 \alpha$ protein levels in spite of a lower Hif $1 \alpha$ mRNA abundance under normoxia that could represent a compensatory response to HIF $1 \alpha$ stabilization.

The upregulation of glucose metabolism on Pink1 loss reported here apparently contrasts with a previous study reporting impaired glucose uptake in Pink1 KO neurons ${ }^{18,26}$. While reasons for this discrepancy are unclear, it should be noted that we found both increased glucose uptake and glycolysis rates at $\sim 5 \mathrm{mM}$ glucose concentration, instead at the very low $(0-2 \mathrm{mM})$ glucose concentrations previously used ${ }^{18,26}$. Furthermore, we confirmed the increased glucose consumption using in vivo settings, as well as the requirement for HIFl $\alpha$-enhanced glycolysis to maintain the high proliferative status of Pink1-null cells. We were surprised that the molecular mechanism identified in this study results in a proliferative phenotype in dividing Pink1 KO cells. Interestingly, PD patients harbouring mutant PINK1 were reported to have increased astroglial proliferation ${ }^{27}$, which could be accounted for by the metabolic alterations described here. In line with this observation, it has been shown that the loss of function of the downstream PINK1 target, PARKIN ${ }^{5,6}$ - as well as the loss of function of other PD-linked genes-is associated with increased cancer prevalence ${ }^{28}$. Therefore, it seems likely that PINK1 regulates cell proliferation through PARKIN. In addition, our data, showing enhanced proliferating activity of neural stem cells in the Pink1-null mice brains, suggests a potentially unexpected key regulatory role for PINK1 in the metabolic adaptation of stem cells. 

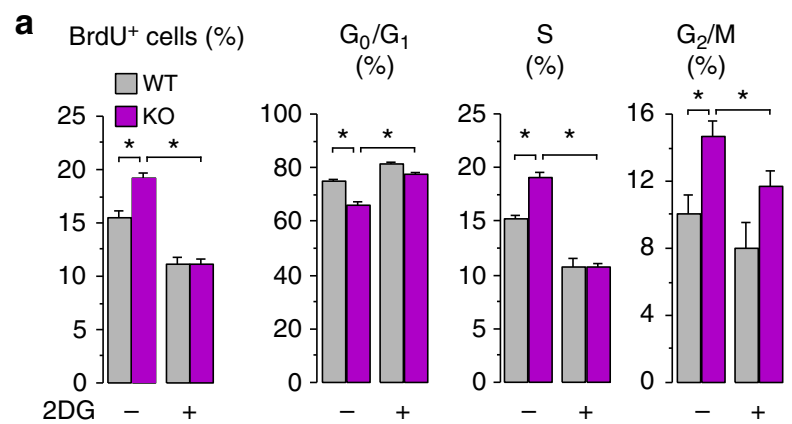

b Cell number $\left(\times 10^{4}\right)$

C
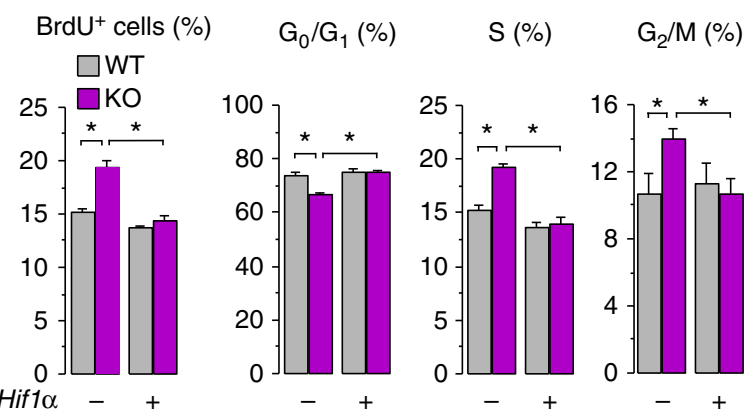

d

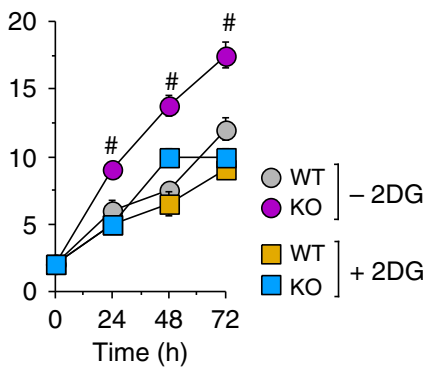

d Cell number $\left(\times 10^{4}\right)$
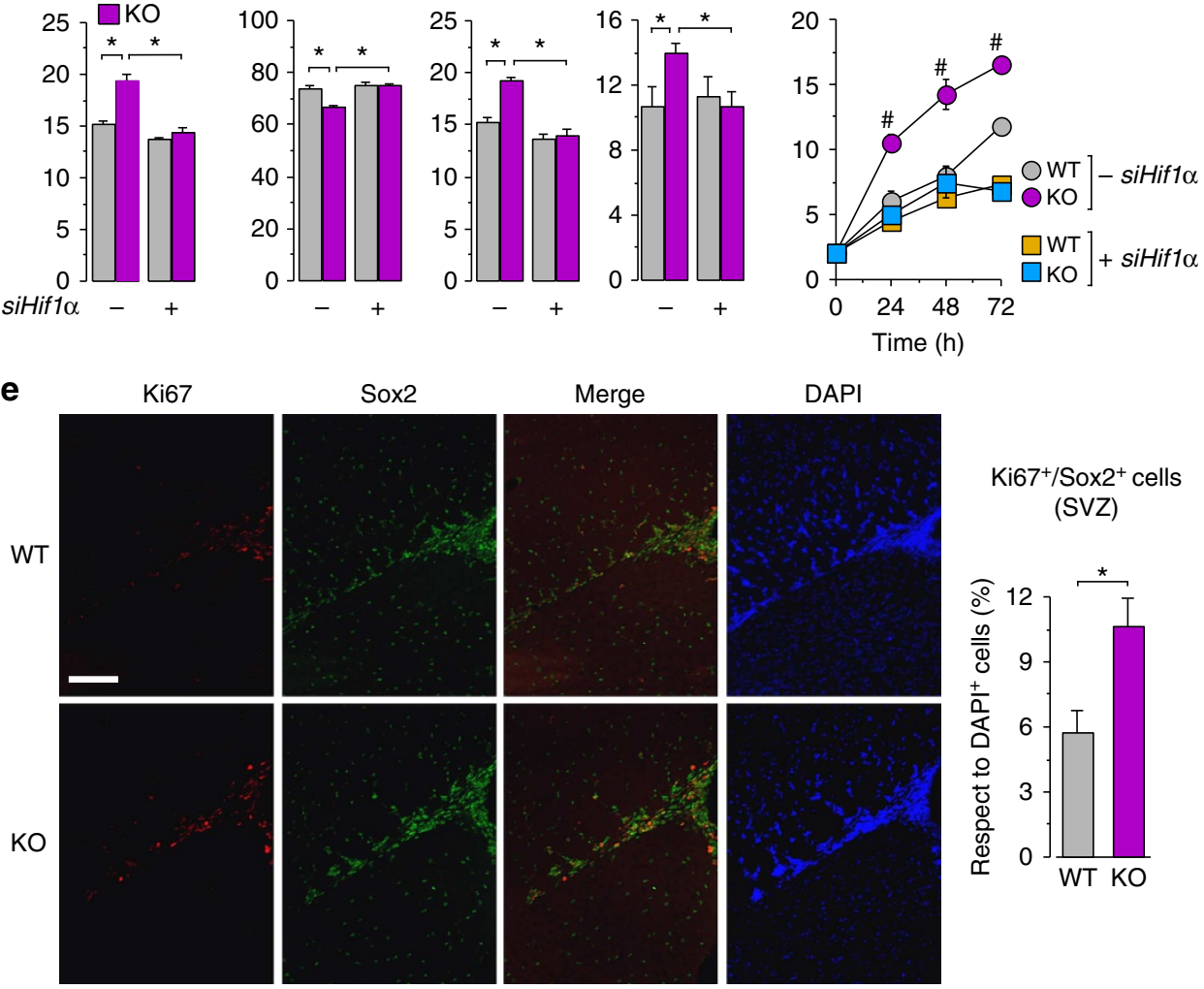

$\mathrm{Ki}^{+} 7^{+} / \mathrm{Sox} 2^{+}$cells (SVZ)

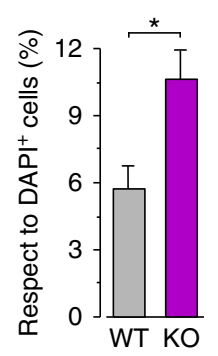

Figure 5 | Increased cell proliferation by Pink1 loss requires HIF1a. (a) Proportion of BrdU incorporation into DNA and cell cycle phases, and (b) cell growth in WT and Pink1 KO MEF after $72 \mathrm{~h}$ in the absence (denoted as -2DG) or in the presence ( $+2 \mathrm{DG}$ ) of the glucose-metabolizing inhibitor, 2-deoxyglucose (2DG, $1 \mathrm{mM}$ ). (c) Proportions of BrdU incorporation into DNA and cell cycle phases, and (d) cell growth in WT and Pink1 KO MEF $72 \mathrm{~h}$ after transfection with siHif1 $\alpha(+$ siHifl $\alpha$ ) or siControl (denoted as -siHif1 $\alpha$ ). (e) Ki67, Sox2 and DAPI immunostaining in the subventricular zone of WT and Pink1 $\mathrm{KO}$ mouse brain, and the corresponding quantification. ${ }^{\star} P<0.05$; ${ }^{\#} P<0.05$ versus all other conditions (analysis of variance followed by Bonferroni test; $n=3-4$ independent experiments). All data are expressed as mean \pm s.e.m. Scale bar, $100 \mu \mathrm{m}$.

Whether PD-relevant loss-of-function mutations on the PINK1 gene confer the high glycolytic phenotype that we describe here deserves further investigation; however, this is likely to be the case since such mutations also lead to mitochondrial oxidative phosphorylation defects ${ }^{12}$ that are responsible for the switch from mitochondrial oxidative to glycolytic metabolism ${ }^{16}$. Some PINK1 single nucleotide polymorphic genotypes are associated with type 2 diabetes and obesity ${ }^{29}$, thus further studies focusing on glucose homeostasis and PD may be worth pursuing. Besides contributing to the observed enhanced proliferative rates detected in Pink1-null fibroblasts, the metabolic reprogramming observed on loss of Pink1 could also sustain mitochondrial proliferation in non-dividing cells such as neurons. In line with this concept, pink1 mutant flies activate a signalling pathway that attempts to compensate for mitochondrial dysfunction by inducing mitochondrial proliferation in post-mitotic cells ${ }^{30}$. The metabolic re-wiring identified in our study may also contribute to cellular damage on PINK1 loss. In this context, post-mitotic neurons subjected to increased glycolytic rate show oxidative stress-mediated neurodegeneration as a consequence of a compensative decreased PPP rate ${ }^{15}$. Our data showing such a PPP to glycolysis shift in Pink1-deficient cells, including neurons, support the notion that such a mechanism likely contributes to the Pink1 loss-associated neurodegeneration in PD.

\section{Methods}

Ethical statement regarding the use of animals. Mice were bred at the Animal Experimentation Unit of the University of Salamanca, and all protocols were 
a

$$
\begin{gathered}
\text { Mitochondrial } \\
\mathrm{O}_{2}^{\circ-} \text { detection } \\
\text { (neurons) }
\end{gathered}
$$

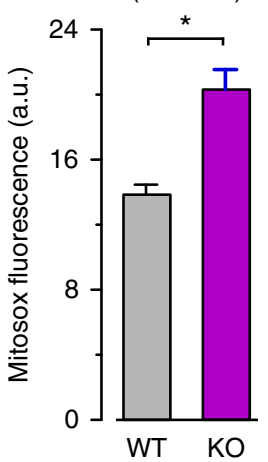

b

$\mathrm{BrdU}^{+}$
neurons

(\%)

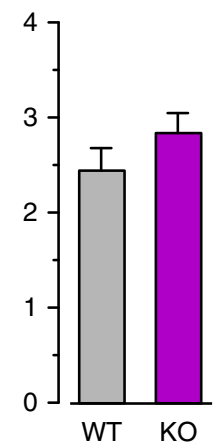

C

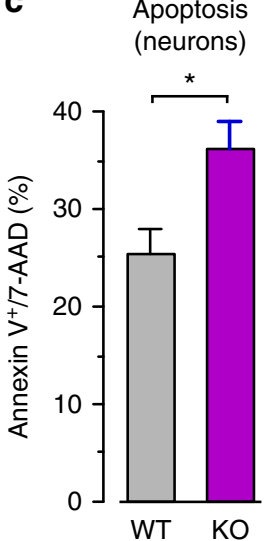

Figure 6 | Loss of Pink1 increases mitochondrial ROS and apoptosis in neurons. (a) Rate of mitochondrial $\mathrm{O}_{2}^{\bullet-}$ detection in WT and Pink1 KO mice primary neurons. (b) Proportion of BrdU incorporation into DNA of WT and Pink1 KO neurons. (c) Proportion of apoptosis in WT and Pink1 KO neurons, as assessed by the proportion of annexin V-positive/7-AAD-negative cells, determined by flow cytometry. Data are expressed as mean \pm s.e.m. ${ }^{\star} P<0.05$ (Student's $t$-test; $n=3-4$ independent experiments).

approved by the Bioethics Committee of the University of Salamanca in accordance with the Spanish legislation (RD53/2013). Pink1 knockout mice were generated by Lexicon Genetics (The Woodlands, Texas, USA); back-crossed for at least nine generations with C57Bl/6J WT mice for the experiments and bred under homozygosis.

Cell cultures. MEF were prepared from fetal (E13.5) Pink1-/- $($ Pink1 KO) and Pink $1^{+1+}$ (WT) offspring. Cells were seeded $\left(10^{5} \mathrm{cells} \mathrm{cm}^{-2}\right)$ in high glucose (25 mM) DMEM (Sigma, Madrid, Spain) with 10\% fetal calf serum (Roche Diagnostics, Heidelberg, Germany) and L-glutamine $(4 \mathrm{mM})$, and incubated at $37^{\circ} \mathrm{C}$ in a humidified $5 \% \mathrm{CO}_{2}$-containing atmosphere. Cortical neurons in primary culture were prepared from fetal (E15.5) WT and PINK1 KO mice. Cells were seeded at $1.8 \times 10^{5} \mathrm{cells}_{\mathrm{sm}}^{-2}$ in cell culture plastic dishes previously coated with poly-D-lysine $\left(15 \mu \mathrm{g} \mathrm{ml}^{-1}\right)$ in neurobasal medium containing $2 \%$ of $\mathrm{B}-27$ supplement (Gibco Brl-Life Technologies, Grand Island, NJ, USA) and $2 \mathrm{mM}$ $\mathrm{L}$-glutamine. Neurons were incubated at $37^{\circ} \mathrm{C}$ in a humidified $5 \% \mathrm{CO}_{2}$-containing atmosphere; at day second, the medium was replaced and neurons were used on the seventh or eighth day in vitro.

RNA interference. To knockdown HIF1 $\alpha$, we used the stealth/siRNA (siHifl $\alpha$ ) duplex oligonucleotide $5^{\prime}$-CAAGCAGCAGGAAUUGGAACAUUAU-3'; as controls (siControl), we used the scrambled non-sense siRNA 5'-CAACGAGGA UAAGGUCAAUAGCUAU-3' (Invitrogen, Paisley, UK).

Plasmids. To confine the expression of the antioxidant enzymes GCL and catalase to mitochondria, the mitochondrial-tagged full-length cDNA encoding GCL (mitoGCL), generated in our laboratory as described ${ }^{23}$, and that of catalase (mitoCAT), a generous gift from J. A. Enriquez (Centro Nacional de Investigaciones Cardiovasculares, Madrid, Spain, were used. Both mitoGCL and mitoCAT were subcloned into pIRES2-EGFP (Invitrogen) for transfections. As controls, we used the empty plasmid (pIRES2-EGFP). Full-length cDNA encoding human Hifl $\alpha$ was a generous gift from S. Cadenas (Centro de Biología Molecular Severo Ochoa, Madrid, Spain).

Site-directed mutagenesis. A mutant form of Hif $1 \alpha$ cDNA refractory to siHifl $\alpha$ was generated using the site-directed mutagenesis QuikChange XL kit (Stratagene, La Jolla, CA, USA), followed by DpnI digestion. The forward and reverse oligonucleotides of the sequence $5^{\prime}$-TCACTTTTTCAAGCTGTTGGGATC GGGACTTTATTACAGCAGCC-3', carrying silent third-codon base point mutations (mutant nucleotides underlined) was used.

Cell transfections and treatments. Transfection of MEF or neurons with siRNA duplexes were performed using Lipofectamine RNAiMAX reagent (Life Technologies), using $100 \mathrm{nM}$ (final concentration) of the siRNA following the manufacturer' instructions, and cells were used after 3 days. For plasmid transfections, $1.6 \mu \mathrm{g}$ (per $10^{3}$ cells) of the plasmid was mixed with $1 \mu \mathrm{M}$ polyethylenimine (Sigma) and preincubated for $10 \mathrm{~min}$ at room temperature in
Optimem medium (Invitrogen). Cells were then incubated with this polyethylenimine/DNA-containing mixture at $37^{\circ} \mathrm{C}$ for $1 \mathrm{~h}$, followed by washing with PBS and further incubated in the corresponding culture medium for $24 \mathrm{~h}$. The fulllength cDNA encoding human Hifl $\alpha$, or its siHif $\alpha$-refractory mutant form (obtained by site-directed mutagenesis as described above), were also used in cotransfection using Lipofectamine RNAiMAX, each with siHifl $\alpha$ or siControl for $24 \mathrm{~h}$. In some experiments, MEF cells were incubated with GSH-E) (100 $\mu \mathrm{M}$ for $24 \mathrm{~h}$ ) or with 2-deoxy-D-glucose (2DG) (1 mM for $72 \mathrm{~h})$.

Assessment of cell proliferation. This was achieved by BrdU incorporation into DNA followed by flow cytometric analysis after a 3-h pulse with BrdU $\left(10 \mathrm{mg} \mathrm{ml}^{-1}\right)$ using the APC BrdU Flow Kit (Becton Dickinson Biosciences, Franklin Lakes, NJ, USA). The proportions of cell cycle phases were also determined by flow cytometric analyses of 7-amino-actinomycin D (7-AAD)-stained cells. Cell proliferation was also confirmed by direct counting under light microscopy.

Real transcriptase quantitative PCR analysis. This was performed in total RNA samples, purified from MEF or neurons using a commercially available kit (Sigma), utilizing the Power SYBR Green RNA-to- $C_{\mathrm{T}}$ 1-Step kit (Applied Biosystems, Township, USA). Reverse transcription was performed for $30 \mathrm{~min}$ at $48^{\circ} \mathrm{C}$, and PCR conditions were $10 \mathrm{~min}$ at $95^{\circ} \mathrm{C}$ followed by 40 cycles of $15 \mathrm{~s}$ at $95^{\circ} \mathrm{C}$ plus $1 \mathrm{~min}$ at $60^{\circ} \mathrm{C}$ using the primers previously described ${ }^{31}$ (Supplementary Table 2) (purchased from Thermo Scientific, Offenbach, Germany). The mRNA abundance of each transcript was normalized to the B-actin mRNA abundance obtained in the same sample. The resulting normalized values of the Pink1 knockout samples were expressed as the fold change compared with the corresponding normalized values of the WT samples.

MicroRNA array. RNA was prepared from the cerebral cortex of 6-month-old male mice (eight samples in total, four replicates for each genotype). The RNA quality was confirmed using an Agilent 2100 Bioanalyzer. Detailed experimental protocols and raw data were deposited in ArrayExpress under accession E-MTAB2462. Differential expression was analysed using R/Bioconductor through standard analysis pipelines.

Western blot. Cells or muscle tissue were lysed in $2 \%$ sodium dodecyl sulphate, 2 mM EDTA, 2 mM EGTA, $50 \mathrm{mM}$ Tris, $\mathrm{pH}$ 7.5, supplemented with phosphatase inhibitors $\left(1 \mathrm{mM} \mathrm{Na}_{3} \mathrm{VO}_{4}, 50 \mathrm{mM} \mathrm{NaF}\right)$ and protease inhibitors $(100 \mu \mathrm{M}$ phenylmethylsulphonyl fluoride, $50 \mu_{\mathrm{g} \mathrm{ml}}^{-1}$ anti-papain, $50 \mu \mathrm{g} \mathrm{ml}^{-1}$ pepstatin, $50 \mu \mathrm{g} \mathrm{ml}^{-1}$ amastatin, $50 \mu \mathrm{g} \mathrm{ml}^{-1}$ leupeptin, $50 \mu \mathrm{g} \mathrm{ml}^{-1}$ bestatin and $50 \mu \mathrm{g} \mathrm{ml}^{-1}$ soybean trypsin inhibitor), stored on ice for $30 \mathrm{~min}$ and boiled for $10 \mathrm{~min}$. Aliquots of the extracts were subjected to sodium dodecyl sulphate polyacrylamide gel electrophoresis (MiniProtean, Bio-Rad, Hercules, CA, USA) and blotted with antibodies overnight at $4{ }^{\circ} \mathrm{C}$. Signal detection was performed with an enhanced chemiluminescence kit (ECL Plus western blotting detection reagent from GE Healthcare, Piscataway Township, NJ, USA). Antibodies used were anti-HIF1 $\alpha$ (1:250; ab16066; Abcam, Cambridge Science Park, Cambridge, UK), anti-PINK1 (1:500; BC100-494; Novus Biologicals, Littleton, CO, USA), anti-HK2 (1:500; sc-6521; Santa Cruz Biotechnology, Dallas, TX, USA), anti- $\beta$-actin (1:30,000; A5441; Sigma), $\alpha$-tubulin (1:2,000; T5168, Sigma), anti-GAPDH (1:40,000; AM4300; Life Technologies, Grand Island, NY, USA), anti-PDK1 (1:1,000; ADIKAP-PK112; Stressgen-Enzo Life Sciences, Farmingdale, NY, USA), anti-GLUT1 (1:500; 07-1401; EMD Millipore Corporation, Billerica, MA, USA) and antiGLUT3 (1:250; sc-74497; Santa Cruz Biotechnologies). After incubation with horseradish peroxidase-conjugated goat anti-rabbit IgG (Santa Cruz Biotechnologies), goat anti-mouse IgG (Santa Cruz Biotechnologies), or rabbit anti-goat IgG (Santa Cruz Biotechnologies) (all at 1:10,000 dilution), membranes were immediately incubated with the enhanced chemiluminescence kit SuperSignal West Dura (Pierce, Thermo Scientific, Illinois, USA) for 5 min or Immobilon Western Chemiluminescent HRP Substrate (Merck Millipore; Darmstadt, Germany) for $1 \mathrm{~min}$, before exposure to Kodak XAR-5 film for 1-5 min, and the autoradiograms scanned. Biologically independent replicates $(2-5)$ were always performed; a representative western blot is shown in the main article, and the replicates are shown in the Supplementary Information. The protein abundances were measured by densitometry of the bands on the films using ImageJ 1.48u4 software (National Institutes of Health, USA), and were normalized against the corresponding loading control ( $\beta$-actin or $\alpha$-tubulin). The protein abundance was calculated as the ratio of the normalized protein of the Pink1 KO cells relative to that of the WT, and the resulting values were used for the statistical analysis.

Mitochondrial function parameters and ROS determination. Cells were collected and suspended in $0.1 \mathrm{M}$ potassium phosphate buffer ( $\mathrm{pH} 7.0$ ). After freeze/thawing three times to ensure cellular disruption, $\mathrm{NADH}-\mathrm{CoQ} 1$ reductase (complex I), succinate-cytochrome $c$ reductase (complex II-III), cytochrome $c$ oxidase (complex IV) and citrate synthase activities were determined as previously described $^{32} \mathrm{PDH}$ activity was determined in intact mitochondria, isolated as previously described ${ }^{23}$ as the rate of $\left[1{ }^{-14} \mathrm{C}\right]$ pyruvate decarboxylation to ${ }^{14} \mathrm{CO}_{2}$ 
(ref. 33). The mitochondrial membrane potential $\left(\Delta \psi_{\mathrm{m}}\right)$ was assessed using MitoProbe $\mathrm{DiIC}_{1}(5)$ Assay Kit for flow cytometry (Molecular Probes Europe BV, Leiden, Netherlands). $\Delta \psi_{\mathrm{m}}$ values were expressed as percentages, using carbonyl cyanide 4-(trifluoromethoxy)phenylhydrazone (FCCP; $10 \mu \mathrm{M}$ ) to define the $0 \%$ $\Delta \psi_{\mathrm{m}}$ values. Mitochondrial superoxide was assessed in intact cells using the fluorescent MitoSox probe (Invitrogen) by flow cytometry, and whole cell-derived $\mathrm{H}_{2} \mathrm{O}_{2}$ was measured, in intact cells, using the fluorescent AmplexRed probe (Invitrogen), following the manufacturers' instructions.

Rate of glucose uptake. Cultured cells were washed twice with PBS and incubated in a Krebs-Ringer phosphate glucose (KRPG) buffer ( $145 \mathrm{mM} \mathrm{NaCl}, 5.7 \mathrm{mM}$ $\mathrm{Na}_{2} \mathrm{PO}_{4}, 4.86 \mathrm{mM} \mathrm{KCl}, 0.54 \mathrm{mM} \mathrm{CaCl}_{2}, 1.22 \mathrm{mM} \mathrm{MgSO}_{4}$ and $5.0 \mathrm{mM}$ glucose, $\mathrm{pH}$ 7.4) at $37^{\circ} \mathrm{C}$ in the $\mathrm{CO}_{2}$ incubator. After $1 \mathrm{~h}, 10 \mu \mathrm{l}$ of $\left[1-{ }^{14} \mathrm{C}\right]-2$-deoxyglucose ( $60 \mathrm{mCi} \mathrm{mmol}^{-1}$; Amersham) was added to the KRPG buffer to a final radioactivity of $0.2 \mu \mathrm{Ci} \mathrm{ml}^{-1}$ and cells were incubated for a further 5,15 and $25 \mathrm{~min}$. At the end of each of these periods of time, the radioactive media was removed and subsequently used to assess the specific radioactivity; cells were rapidly washed three times with ice-cold PBS and immediately lysed with $0.6 \mathrm{ml}$ of $0.1 \mathrm{M} \mathrm{NaOH}$. A $0.5 \mathrm{ml}$ lysate aliquot was used for radioactivity determination using a liquid scintillation counter, and the rest was used to determine protein concentration. The rate of glucose uptake was calculated from the radioactivity versus time regression slopes, which were linear up to the $25 \mathrm{~min}$ of incubation. At least four different wells were used for each sample, and at least three different culture preparations were used per condition.

Rates of glycolysis and PPP. These were measured in suspended cells $\left(4-5 \times 10^{5}\right.$ cells), incubated in KRPG buffer in the presence of $5 \mu \mathrm{Ci}$ of $\mathrm{D}-\left[3-{ }^{3} \mathrm{H}\right]$ glucose, $0.5 \mu \mathrm{Ci} \mathrm{ml}{ }^{-1}$ of $\mathrm{D}-\left[1^{-14} \mathrm{C}\right]$ glucose or $1 \mu \mathrm{Ci} \mathrm{ml}{ }^{-1}$ of $\left[6^{-14} \mathrm{C}\right]$ glucose and $5 \mathrm{mM}$ $\mathrm{D}$-glucose in sealed vials. The glycolytic flux was measured by assaying the rate of ${ }^{3} \mathrm{H}_{2} \mathrm{O}$ production from $\left[3-{ }^{3} \mathrm{H}\right]$ glucose, and the PPP flux as the difference between $\left[1-{ }^{14} \mathrm{C}\right]$ glucose and $\left[6-{ }^{14} \mathrm{C}\right]$ glucose incorporated into ${ }^{14} \mathrm{CO}_{2}$, as detailed previously ${ }^{15}$. In vivo blood lactate production was determined $15 \mathrm{~min}$ after a tail vein injection of $5 \mu \mathrm{Ci}$ of $\left[\mathrm{U}_{-}{ }^{14} \mathrm{C}\right]$ glucose. Blood $\left[\mathrm{U}_{-}{ }^{14} \mathrm{C}\right]$ lactate was separated from $\left[\mathrm{U}-{ }^{14} \mathrm{C}\right]$ glucose by ion exchange chromatography (Dowex AG-1 $\times 8$ ) as we previously described ${ }^{15}$, and measured by liquid scintillation counting. Lactate and glucose concentrations were measured in either cell culture media at the indicated times, or in deproteinized blood samples, by enzymatic analysis spectrophotometrycally ${ }^{15}$.

Flow cytometric analysis of apoptotic neuronal death. Neurons were carefully detached from the plates using $1 \mathrm{mM}$ EDTA (tetrasodium salt) in PBS. APCconjugated annexin-V and 7-amino-actinomycin D (7-AAD) (Becton Dickinson Biosciences) were used to determine quantitatively the percentage of apoptotic neurons by flow cytometry. Cells were stained with annexin V-APC and 7-AAD in binding buffer (100 mM HEPES, $140 \mathrm{mM} \mathrm{NaCl}, 2.5 \mathrm{mM} \mathrm{CaCl}_{2}$ ), according to the manufacturer's instructions, and $3 \times 10^{5}$ cells were analysed, in four replicates per condition, on a FACScalibur flow cytometer $(15 \mathrm{~mW}$ argon ion laser tuned at $488 \mathrm{~nm}$; CellQuest software, Becton Dickinson Biosciences). The annexin V-APCstained neurons that were 7-AAD-negative were considered to be apoptotic. The analyser threshold was adjusted on the flow cytometer channel to exclude most of the subcellular debris to reduce the background noise owing to the neurite disruption during neuronal detaching. Data were expressed as percentages.

Inmunohistochemistry. After deep anaesthesia, mice were perfused intraaortically with $0.9 \% \mathrm{NaCl}$, followed by $4 \%(\mathrm{w} / \mathrm{v})$ paraformaldehyde, $0.2 \%(\mathrm{w} / \mathrm{v})$ picric acid in $0.1 \mathrm{M}$ phosphate buffer ( $\mathrm{pH}$ 7.4). Brains were dissected and post fixed overnight and cryoprotected before $20-\mu \mathrm{m}$ thick coronal sections were obtained with a freezing-sliding cryostate (Leica CM 1950 AgProtect, Leica, Nussloch, Germany). Sections were incubated with anti-Sox2 antibody (1:4,000; Abcam, ab79351) that stains stem cells, overnight at $4{ }^{\circ} \mathrm{C}$, followed by anti-Ki67 antibody (1:200; Clone SP6; Thermo Scientific), which is expressed in proliferating cells, for $1 \mathrm{~h}$ at room temperature. Sections were further incubated with Cy3 anti-rabbit for Sox, and Cy2 anti-mouse for Ki67, followed by DAPI staining. Mounted sections were examined by epifluorescence under a Nikon Inverted microscope (Eclipse Ti-E, Japan) equipped with a precentered fibre illuminator (Nikon Intensilight C-HGFI, Tokyo, Japan) and B/W CCD digital camera (Hamamatsu ORCA-ER, Hamamatsu, Japan). The total number of cells $\left(\mathrm{DAPI}^{+}\right)$and $\mathrm{Ki} 7^{+} / \mathrm{Sox} 2^{+}$cells were counted in $0.3 \mathrm{~mm}^{2}$ sections from three slices/mouse.

Protein determinations. Protein concentrations were determined in the cell suspensions, lysates or in parallel cell culture incubations after solubilization with $0.1 \mathrm{M} \mathrm{NaOH}$. Protein concentrations were determined as described ${ }^{34}$ using bovine serum albumin as standard.

Statistical analysis. All measurements in cell culture were carried out at least in three different culture preparations, and the results are expressed as the mean \pm s.e.m. For in vivo experiments, we used at least four animals per condition.
For the comparisons between two groups of values, the statistical analysis of the results was performed by the Student's $t$-test. For multiple values comparisons, we used one-way analysis of variance followed by Bonferroni test. The statistical analysis was performed using the SPSS 16.0 software for Macintosh. In all cases, $P<0.05$ was considered significant.

\section{References}

1. Exner, N., Lutz, A. K., Haass, C. \& Winklhofer, K. F. Mitochondrial dysfunction in Parkinson's disease: molecular mechanisms and pathophysiological consequences. EMBO J. 31, 3038-3062 (2012).

2. Kitada, T. et al. Mutations in the parkin gene cause autosomal recessive juvenile parkinsonism. Nature 392, 605-608 (1998).

3. Valente, E. M. et al. Hereditary early-onset Parkinson's disease caused by mutations in PINK1. Science 304, 1158-1160 (2004).

4. Beilina, A. et al. Mutations in PTEN-induced putative kinase 1 associated with recessive parkinsonism have differential effects on protein stability. Proc. Natl Acad. Sci. USA 102, 5703-5708 (2005).

5. Clark, I. E. et al. Drosophila pink1 is required for mitochondrial function and interacts genetically with parkin. Nature 441, 1162-1166 (2006).

6. Park, J. et al. Mitochondrial dysfunction in Drosophila PINK1 mutants is complemented by parkin. Nature 441, 1157-1161 (2006).

7. Corti, O. \& Brice, A. Mitochondrial quality control turns out to be the principal suspect in parkin and PINK1-related autosomal recessive Parkinson's disease. Curr. Opin. Neurobiol. 23, 100-108 (2013).

8. Dagda, R. K. et al. Loss of PINK1 function promotes mitophagy through effects on oxidative stress and mitochondrial fission. J. Biol. Chem. 284, 13843-13855 (2009).

9. Hasson, S. A. et al. High-content genome-wide RNAi screens identify regulators of parkin upstream of mitophagy. Nature 504, 291-295 (2013).

10. McCoy, M. K. \& Cookson, M. R. Mitochondrial quality control and dynamics in Parkinson's disease. Antioxid. Redox. Signal. 16, 869-882 (2012).

11. Gegg, M. E., Cooper, J. M., Schapira, A. H. \& Taanman, J. W. Silencing of PINK1 expression affects mitochondrial DNA and oxidative phosphorylation in dopaminergic cells. PLoS ONE 4, e4756 (2009).

12. Morais, V. A. et al. Parkinson's disease mutations in PINK1 result in decreased Complex I activity and deficient synaptic function. EMBO Mol. Med. 1, 99-111 (2009).

13. Unoki, M. \& Nakamura, Y. Growth-suppressive effects of BPOZ and EGR2, two genes involved in the PTEN signaling pathway. Oncogene 20, 4457-4465 (2001).

14. Lunt, S. Y. \& Vander Heiden, M. G. Aerobic glycolysis: meeting the metabolic requirements of cell proliferation. Annu. Rev. Cell Dev. Biol. 27, 441-464 (2011).

15. Herrero-Mendez, A. et al. The bioenergetic and antioxidant status of neurons is controlled by continuous degradation of a key glycolytic enzyme by APC/CCdh1. Nat. Cell Biol. 11, 747-752 (2009).

16. Semenza, G. L. HIF-1 mediates metabolic responses to intratumoral hypoxia and oncogenic mutations. J. Clin. Invest. 123, 3664-3671 (2013).

17. Camps, C. et al. Integrated analysis of microRNA and mRNA expression and association with HIF binding reveals the complexity of microRNA expression regulation under hypoxia. Mol. Cancer 13, 28 (2014).

18. Gandhi, S. et al. PINK1-associated Parkinson's disease is caused by neuronal vulnerability to calcium-induced cell death. Mol. Cell 33, 627-638 (2009).

19. Kim, J. W., Tchernyshyov, I., Semenza, G. L. \& Dang, C. V. HIF-1-mediated expression of pyruvate dehydrogenase kinase: a metabolic switch required for cellular adaptation to hypoxia. Cell Metab. 3, 177-185 (2006).

20. Brunelle, J. K. et al. Oxygen sensing requires mitochondrial ROS but not oxidative phosphorylation. Cell Metab. 1, 409-414 (2005).

21. Calvani, M., Comito, G., Giannoni, E. \& Chiarugi, P. Time-dependent stabilization of hypoxia inducible factor-1alpha by different intracellular sources of reactive oxygen species. PLoS ONE 7, e38388 (2012).

22. Patten, D. A. et al. Hypoxia-inducible factor-1 activation in nonhypoxic conditions: the essential role of mitochondrial-derived reactive oxygen species. Mol. Biol. Cell 21, 3247-3257 (2010).

23. Quintana-Cabrera, R. et al. $\gamma$-Glutamylcysteine detoxifies reactive oxygen species by acting as glutathione peroxidase-1 cofactor. Nat. Commun. 3, 718 (2012).

24. Priyadarshini, M., Tuimala, J., Chen, Y. C. \& Panula, P. A zebrafish model of PINK1 deficiency reveals key pathway dysfunction including HIF signaling. Neurobiol. Dis. 54, 127-138 (2013).

25. Lin, W. et al. Loss of PINK1 attenuates HIF-1alpha induction by preventing 4E-BP1-dependent switch in protein translation under hypoxia. J. Neurosci. 34, 3079-3089 (2014).

26. Scheele, C. et al. Altered regulation of the PINK1 locus: a link between type 2 diabetes and neurodegeneration? FASEB J. 21, 3653-3665 (2007).

27. Prestel, J. et al. Clinical and molecular characterisation of a Parkinson family with a novel PINK1mutation. J. Neurol. 255, 643-648 (2008). 
28. Devine, M. J., Plun-Favreau, H. \& Wood, N. W. Parkinson's disease and cancer: two wars, one front. Nat. Rev. Cancer 11, 812-823 (2011).

29. Franks, P. W. et al. Genomic variants at the PINK1 locus are associated with transcript abundance and plasma nonesterified fatty acid concentrations in European whites. FASEB J. 22, 3135-3145 (2008).

30. Tufi, R. et al. Enhancing nucleotide metabolism protects against mitochondrial dysfunction and neurodegeneration in a PINK1 model of Parkinson's disease. Nat. Cell Biol. 16, 157-166 (2014).

31. Brix, B., Mesters, J. R., Pellerin, L. \& Johren, O. Endothelial cell-derived nitric oxide enhances aerobic glycolysis in astrocytes via HIF-1alpha-mediated target gene activation. J. Neurosci. 32, 9727-9735 (2012).

32. Bolaños, J. P., Peuchen, S., Heales, S. J. R., Land, J. M. \& Clark, J. B. Nitric oxide-mediated inhibition of the mitochondrial respiratory chain in cultured astrocytes. J. Neurochem. 63, 910-916 (1994).

33. Paxton, R. \& Sievert, L. M. An improved assay for pyruvate dehydrogenase in liver and heart. Biochem. J. 277, 547-551 (1991).

34. Lowry, O. H., Rosebrough, N. J., Lewis-Farr, A. \& Randall, R. J. Protein measurement with the Folin phenol reagent. J. Biol. Chem. 193, 265-275 (1951).

\section{Acknowledgements}

This work was funded by the Spanish Ministerio de Economia y Competitividad (to J.P.B., grant number SAF2013-41177-R), the Instituto de Salud Carlos III (to J.P.B., grant number RD12/0043/0021; to A.A., grant numbers PI12/00685 and RD12/0014/0007), Junta de Castilla y Leon (to J.P.B., SA003U13), the SP3-People-MC-ITN programme of the European Commission (to J.P.B., 608381 TINTIN), and the European Regional Development Fund. I.L.-F. is the recipient of a FPI Fellowship from the MINECO (Spain). The technical assistances of Ms. Monica Carabias, Ms. Monica Resch, Dr Nicoleta Moisoi, Dr Kate Dudek and Dr Jin Li Luo are acknowledged.

\section{Author contributions}

J.P.B. conceived the idea. L.M.M. provided conceptual advice and contributed materials J.P.B., R.R.-A., E.F. and A.A. designed research. R.R.A., I.L.-F., E.F., A.A. and L.M.M. performed research. J.P.B., R.R.A., A.A., E.F. and L.M.M. analysed the data. J.P.B. wrote the manuscript.

\section{Additional information}

Accession codes: Microarray raw data are available in the ArrayExpress database (www.ebi.ac.uk/arrayexpress) under the accession number E-MTAB-2462.

Supplementary Information accompanies this paper at http://www.nature.com/ naturecommunications

Competing financial interests: The authors declare no competing financial interests.

Reprints and permission information is available online at http://npg.nature.com/ reprintsandpermissions/

How to cite this article: Requejo-Aguilar, R. et al. PINK1 deficiency sustains cell proliferation by reprogramming glucose metabolism through HIF1. Nat. Commun. 5:4514 doi: $10.1038 /$ ncomms5514 (2014). 